\title{
Duchenne Muscular Dystrophy in South Korea Based on Data From the National Health Insurance Database: Corticosteroid Use and Bone Health Management
}

\author{
Jin A Yoon \\ Pusan National University Hospital \\ Ho Eun Park \\ Pusan National University Hospital \\ Jinmi Kim \\ Pusan National University Hospital \\ Yong Beom Shin ( $\nabla$ yi0314@gmail.com ) \\ Pusan National University Hospital \\ Jungmin Son \\ Pusan National University Hospital
}

\section{Research Article}

Keywords: Duchenne muscular dystrophy, Corticosteroid, Bone, South Korea

Posted Date: November 30th, 2021

DOl: https://doi.org/10.21203/rs.3.rs-1091648/v1

License: (c) (i) This work is licensed under a Creative Commons Attribution 4.0 International License. Read Full License 


\section{Abstract \\ Background}

This study aimed to determine the current corticosteroid use and bone health management status of patients with Duchenne muscular dystrophy (DMD) in South Korea.

\section{Methods}

Data from the Korean National Health Insurance Database regarding bone status, spine radiography findings, bone mineral density, and laboratory test results were obtained, as well as the proportion of patients with spine and lower limb prostheses, occurrence of scoliosis, and age at scoliosis surgery.

\section{Results}

Deflazacort dose in the ambulant group (aged $<15$ years old) increased by age and year. The maintenance dose of prednisolone and deflazacort for the 15-19 group decreased by year. Among the patients, 12.47\% underwent spine radiography, $23.11 \%$ underwent dual-energy X-ray absorptiometry, and $22.7 \%$ underwent vitamin D tests. Moreover, $40.9 \%$ of the patients were prescribed vitamin D at a mean age of $14.6 \pm 6.1$ years, while $10.22 \%$ were prescribed bisphosphonate at $17.92 \pm 3.4$ years. Further, $16.1 \%$ patients underwent posterior spinal instrumentation and fusion at $14.4 \pm 2.3$ years and $5.3 \%$ underwent anterior spinal instrumentation and fusion at $14.4 \pm 2.3$ years. Ankle-foot orthosis and spine orthosis prescriptions were noted in $4.91 \%$ and $1.84 \%$ of patients, respectively.

\section{Conclusions}

The current status of clinical practice for patients with DMD in South Korea have been presented. It is expected that the findings of this study will contribute to raising awareness on the necessity of establishing a domestic registry in the country for patients with DMD.

\section{Background}

Duchenne muscular dystrophy (DMD) is the most common childhood muscular dystrophy with a worldwide incidence of 1 in 5,000 live male births [1]. A 2007 epidemiological investigation conducted by the Centers for Disease Control in South Korea reported an annual number of 3,459 patients with muscular dystrophy, with the highest proportion shown to have Duchenne or Becker muscular dystrophy, a subtype with severe clinical symptoms, whereas the proportion of those with muscular dystrophy was presumed to be $30-40 \%$ [2]. However, no study has yet provided an established database or clinical information regarding patients with DMD in South Korea.

In the past few decades, most patients with DMD died in their 20s owing to respiratory failure or cardiomyopathy [3,4]. The use of glucocorticoids has been shown to have multiple benefits, including prolonged life expectancy and delayed loss of ambulation, respiratory dependence, and onset of scoliosis $[5,6]$. Multidisciplinary care systems, along with glucocorticoid prescription, related bone health, and orthopedic management, have been proven to preserve the ambulatory and physical functions and prolong survival. Therefore, a shift to more anticipatory therapeutic strategies has been observed, and many clinicians are managing patients based on the DMD care recommendations updated in $2010[7,8]$ and $2018[9,10]$ to provide guidance on the advances in assessments and interventions for DMD. However, uncertainty remains with respect to the appropriate initiation, dosage, and type of glucocorticoid usage. Moreover, a recent expert survey in Asian countries showed that approximately $20 \%$ of clinicians did not use steroids owing to side effects [11], and the regimen also differed in each country. These uncertainties increase the risk of undertreatment or overtreatment, which could confound the results of clinical trials of innovative therapies.

The present study aimed to determine information such as the current corticosteroid use and the related bone health management status of patients with DMD in South Korea based on the Korean National Health Insurance Database and to provide fundamental data for creating and standardizing the national guidelines for DMD treatment in the future.

\section{Methods}

\section{Identification of subjects}

From this database, the data of patients corresponding to G71.0 and the special case V012 according to the Tenth Revision of the International Classification of Diseases main diagnosis and sub-diagnosis were extracted. To screen the patients with DMD, the operational definition was set as a male patient under 40 years old who had been diagnosed before the age of 10 years. To exclude other types of MD, patients who had been prescribed steroids were selectively extracted according to the recent recommendation on the current status of steroid prescription for DMD patients in South Korea [9] to construct a database. In addition, patients who did not demonstrate the typical clinical course, such as those who had been prescribed a wheelchair before 5 years old or had a ventilator prescription before 11 years old, were excluded from the study. The wash-out period was 7 years. The patient screening algorithm using the National Health Insurance claims data is presented in Figure 1. 
We analyzed the number of patients at intervals of 5 years, and if the dates of diagnosis and death followed the onset of recuperation, the mortality date was verified. Regarding the use of corticosteroids, whether the patient had been given a steroid prescription, the percentage of prednisolone or deflazacort among all prescriptions, the patient's age when the prescription was given, and the dose prescribed for each age group were examined.

Regarding bone status, spine radiography, dual-energy X-ray absorptiometry (DXA), and vitamin D laboratory tests were performed, and the interval of these tests was determined. The age when spine and lower limb prostheses were prescribed was analyzed. In addition, to estimate when the loss of gait ability occurred, we checked when a wheelchair prescription was issued. The data of orthosis prescription were extracted from the benefits payment table of 2016-2018 when orthosis prescription was included for insurance benefit. In addition, whether scoliosis surgery had been performed and the age at which the surgery was performed were checked.

\section{Ethics statement}

The study was approved by the Institutional Review Board of the 00 National University Hospital (approval number 1907-008-080) and the National Health Insurance Service of Korea (approval number REQ0000030402). The requirement for informed consent was waived because secondary data were used.

\section{Results}

From 2002 to 2018, approximately 479 patients met the diagnostic criteria (Figure 1). Among the DMD patients with corticosteroid prescription, the late non-ambulatory patients (aged $>20$ years) increased over the years. A total of $52(10.8 \%)$ patients died, and the mean age at death increased by year (Table 1).

Table 1. Number of DMD patients with corticosteroid prescription and age of death by year.

(A) Number of DMD patients with corticosteroid prescription.

\begin{tabular}{|c|c|c|c|c|c|c|c|c|c|c|c|c|c|c|c|c|c|}
\hline Age & 2002 & 2003 & 2004 & 2005 & 2006 & 2007 & 2008 & 2009 & 2010 & 2011 & 2012 & 2013 & 2014 & 2015 & 2016 & 2017 & 2018 \\
\hline $1-4$ & 25 & 32 & 35 & 35 & 42 & 50 & 47 & 45 & 48 & 42 & 40 & 34 & 40 & 36 & 35 & 30 & 19 \\
\hline $5-9$ & 72 & 94 & 113 & 135 & 126 & 113 & 114 & 107 & 91 & 93 & 92 & 90 & 78 & 77 & 72 & 72 & 62 \\
\hline $\begin{array}{l}10- \\
14\end{array}$ & 11 & 19 & 42 & 71 & 113 & 137 & 161 & 163 & 167 & 143 & 124 & 118 & 114 & 96 & 96 & 94 & 92 \\
\hline $\begin{array}{l}15- \\
19\end{array}$ & 0 & 0 & 0 & 0 & 0 & 11 & 18 & 41 & 69 & 110 & 131 & 154 & 154 & 158 & 134 & 113 & 105 \\
\hline $\begin{array}{l}20- \\
24\end{array}$ & 0 & 0 & 0 & 0 & 0 & 0 & 0 & 0 & 0 & 0 & 10 & 17 & 38 & 65 & 102 & 124 & 141 \\
\hline$>25$ & 0 & 0 & 0 & 0 & 0 & 0 & 0 & 0 & 0 & 0 & 0 & 0 & 0 & 0 & 0 & 10 & 18 \\
\hline Total & 109 & 145 & 190 & 242 & 283 & 314 & 342 & 357 & 375 & 388 & 398 & 415 & 426 & 432 & 440 & 443 & 433 \\
\hline
\end{tabular}

(B) Mean age of death by year

\begin{tabular}{|llllll|}
\hline $\mathrm{yr}$ & 2009 & 2010 & 2011 & 2012 & 2013 \\
\hline Age & $12.3 \pm 5.0$ & $14.2 \pm 1.7$ & $14.2 \pm 1.7$ & $14.0 \pm 2.8$ & $14.4 \pm 7.4$ \\
\hline
\end{tabular}

\begin{tabular}{|llllll|}
\hline yr & 2014 & 2015 & 2016 & 2017 & 2018 \\
\hline Age & $13.0 \pm 4.0$ & $17.6 \pm 4.5$ & $18.0 \pm 2.8$ & $19.1 \pm 3.2$ & $20.4 \pm 4.2$ \\
\hline
\end{tabular}

The mean age of wheelchair prescription to predict the time of loss of ambulation was $11.9 \pm 3.4$ years. The corticosteroid prescription by age and year from 2009 to 2018 showed proportion of maintenance corticosteroid therapy for non-ambulant patients (age $>20$ years) increased over the years (Figure 2). The proportions of patients with deflazacort and prednisolone prescriptions are presented in Figure 3 and showed similar ratio recently. Mean age of initial corticosteroid prescription by year showed younger in deflazacort compared to prednisolone (Figure 4). The mean prescription dose per day for prednisolone and deflazacort is showed in Figure 5. Deflazacort prescription dose for the ambulant group (age >15 years) increased by age and year. The maintenance dose of prednisolone and deflazacort for those aged 15-19 years decreased by year (Figure 5). 
Among all patients, 65 (13.6\%) underwent spine radiography with a 509.2 \pm 470.5-day interval, $118(24.6 \%)$ underwent DXA within a 1019.4 \pm 903.4-day interval, and 111 (23.2\%) underwent vitamin D level tests. Of these patients, 193 (40.3\%) had vitamin D prescription at a mean age of $12.5 \pm 4.8$ years and $48(10.2 \%)$ had bisphosphonate prescription at a mean age of $17.9 \pm 3.4$ years with a $170.5 \pm 245.4$-day interval (Table 2 ).

Table 2. Status of bone health management in the study population $(\mathrm{N}=479)$.

\begin{tabular}{|ll|}
\hline Characteristics & Total (N=479) \\
\hline Spine radiography, $n(\%)$ & $65(13.6)$ \\
\hline Age at spine radiography, years, mean \pm SD & $13.5 \pm 4.8$ \\
\hline Interval of spine radiography, day, mean \pm SD & $509.2 \pm 470.5$ \\
\hline Dual-energy X-ray absorptiometry (DXA) scan, $n(\%)$ & $118(24.6)$ \\
\hline Age at DXA, years, mean \pm SD & $13.58 \pm 5.1$ \\
\hline Interval of DXA, days, mean \pm SD & $1019.4 \pm 903.4$ \\
\hline Vitamin D level, $n(\%)$ & $111(23.2)$ \\
\hline Age at vitamin D level measurement, year, mean \pm SD & $14.6 \pm 6.1$ \\
\hline Bisphosphonate prescription, $n(\%)$ & $48(10.2)$ \\
\hline Age at bisphosphonate prescription, year, mean \pm SD & $17.9 \pm 3.4$ \\
\hline Interval of bisphosphonate prescription, day, mean \pm SD & $170.5 \pm 245.4$ \\
\hline Vitamin D prescription, $n$ (\%) & $193(40.3)$ \\
\hline Age at vitamin D prescription, year, mean \pm SD & $12.5 \pm 4.8$ \\
\hline
\end{tabular}

With regard to orthopedic management, there were 22 (4.6\%) and 9 (1.9\%) patients from 2016 to 2018 with ankle-foot orthosis and spine orthosis, respectively, as could be verified from the insurance benefits data. Moreover, 77 (16.1\%) patients had posterior spinal instrumentation and fusion at $14.4 \pm$ 2.3 years, and 25 (5.2\%) had anterior spinal instrumentation and fusion at $14.9 \pm 2.1$ years (Table 3 ).

Table 3. Orthopedic and surgical management in the study population $(\mathrm{N}=479)$.

\begin{tabular}{|ll|}
\hline Characteristics & Total (N = 479) \\
\hline Ankle-foot orthosis prescription, $n(\%)$ & $22(4.6)$ \\
\hline Spine orthosis prescription, $n(\%)$ & $9(1.9)$ \\
\hline Posterior spinal instrumentation and fusion, $n(\%)$ & $77(16.1)$ \\
\hline Anterior spinal instrumentation and fusion, $n(\%)$ & $25(5.2)$ \\
\hline Age at posterior fusion, year, mean \pm SD & $14.4 \pm 2.3$ \\
\hline Age at anterior fusion, year, mean \pm SD & $14.9 \pm 2.1$ \\
\hline
\end{tabular}

Orthosis prescription data was extracted from 2016-2018

\section{Discussion}

DMD is the most common subtype of MD with severe clinical symptoms. Patients with DMD show progressive muscle and respiratory weakness, loss of ambulation at the age of 10 years, and have a median life expectancy with ventilatory support ranging from 21.0 to 39.6 years [5]. Most clinicians are aware of the benefits of glucocorticoid therapy to improve life expectancy and preserve respiratory function [8,12]. To the best of our knowledge, this is the first database study to investigate the current status of clinical practice directly related to disease progression in patients with DMD in South Korea. According to the database, the number of patients aged $>20$ years and the mean age at death increased yearly.

\section{Glucocorticoid therapy}

Long-term steroid use in patients with DMD has prolonged life expectancy and changed the overall natural history [13], although their prescription has still not been standardized, and there are mixed opinions about the time of initiation and whether to continue the use of steroids after the loss of ambulation $[11,14,15]$. According to the results of the present study, steroid prescription is mostly not initiated at the time of DMD diagnosis owing to gait abnormalities; this is inconsistent with the findings of recent studies placing emphasis on the benefits of early initiation of steroid therapy before the onset of physical decline $[14,15]$. Deflazacort tended to be increasingly prescribed to younger patients compared with prednisolone; however, the age of 
initiation did not decrease over the years. The long-term outcomes of the many different regimens (up to 29 identified) are not clear. Although the benefits of glucocorticoid therapy are well-established, considering the benefit-to-risk ratio of the drugs, uncertainty remains regarding the appropriate regimen and the use of steroid therapy after the loss of ambulation [16-18]. Although it has been reported that glucocorticoid therapy is effective in terms of maintaining upper limb function and cardiorespiratory function [19], the long-term use of steroids can cause various side effects, such as bone health problems, obesity, and behavioral changes [20], and consensus has not been reached regarding maintaining the prescription of steroids during the nonambulant period. On examining the drug prescription regimen data collected in this study, it was confirmed that the percentage of non-ambulant patients taking steroids increased by year. Previous studies have compared the superiority between prednisolone and deflazacort; however, it is difficult to draw a definite conclusion from these results. Based on the data of this study, the percentage of deflazacort prescriptions was similar to that for prednisolone in recent years. Although deflazacort prescription dose in the ambulant group increased by age and year, the dose prescription for both deflazacort and prednisolone did not reach the recommendation of the current DMD care consideration (prednisolone: $0.75 \mathrm{mg} / \mathrm{kg}$ per day; deflazacort: $0.9 \mathrm{mg} / \mathrm{kg}$ per day). Considering the fact that the recent clinical trials for DMD treatment are excluding the patients not receiving corticosteroid therapy as the recommended regimen, discussion among clinicians is required to confirm the findings of this study

\section{Bone health management}

With regard to glucocorticoid-treated DMD cases, there is a high incidence of glucocorticoid-induced osteoporosis, and the resulting bone fragility may lead to secondary vertebral and long-bone fractures [21]. In the current care considerations, serial spine radiography is recommended over DXA scan to determine asymptomatic bone fragility [10]. In a recent expert study, $60 \%$ of the patients underwent routine bone health assessment, and DXA was the most common method, followed by spine X-rays and biochemical marker assessment [11]. In the present study, among the patients assessed for bone health monitoring, less than $30 \%$ underwent spine radiography, DXA, scan and Vitamin D level examination. DXA was confirmed to be the most commonly used method among all tests. The tests were conducted with longer time intervals than the recommendation. Approximately $40 \%$ of patients were prescribed vitamin D and bisphosphonate; however, considering the additional needs for DXA scan based on our results, the percentage of patients requiring the prescription may also increase.

\section{Orthopedic management}

Orthopedic management of DMD is necessary to minimize joint contractures and prolong ambulatory function as much as possible. A custom-molded night-time ankle-foot orthosis prescription can be used from the ambulatory stage to delay the progression of the equinovarus contracture of the ankle and extend the ambulatory stage; even if the patient becomes wheelchair-bound, it is possible to assume a proper sitting posture by maintaining the ankle joint. In this study, approximately $5 \%$ of the patients were given prescriptions, and as the study data only included 3 years of available benefits payment table records, the actual prescription rate is presumed to be higher. With the onset of the non-ambulatory stage, scoliosis progresses rapidly, causing discomfort in the sitting posture; this can also lead to compromised respiratory function [22]. Monitoring of radiography assessment annually or every 6 months after the confirmatory diagnosis of scoliosis is recommended [10]. The assessment frequency in the applicable age group was judged to be longer than expected in this study.

There is a low-level evidence that spinal orthoses can delay the progression of scoliosis. However, there were cases in which spinal orthosis was prescribed, assuming that the initial mobile curve could be corrected and maintained with the aid of an orthosis [23]. Although we confirmed that it was prescribed to some patients, our result was analyzed during the 3 years for which data were available. Surgery is recommended for functional improvement, sitting balance, and improvement of pain and the quality of life at a young age when a spinal curve of $\geq 20^{\circ}$ has been measured [24,25]. Even with the consideration that corticosteroid therapy slows mild spinal curvature and reduces the necessity of spine surgery [26], the results of our study confirmed that a low percentage of our patients underwent spinal surgery [27], and the age of undergoing surgery was found to be higher than in the early 10 s, which is the aged at which patients become wheelchair-bound [28]. As posterior spinal instrumentation and fusion are recommended in non-ambulatory individuals, the percentage of posterior approach was three time higher than anterior approach in our data.

This study describes the current status of corticosteroid use and bone health management related to DMD, and it is the first study in a South Korean population in this regard.

There are some limitations to our study. First, we could not extract a complete list of patients with DMD from those with MD solely based on the diagnosis codes owing to the limitations of big data. In this study, we identified patients with MD who were prescribed corticosteroids and had the typical clinical course of DMD for analysis. Furthermore, as many patients with DMD are diagnosed based on non-covered genetic testing instead of a muscle biopsy or EMG as a result of advances in diagnostic techniques, we could not perform an epidemiological analysis encompassing incidence and time of diagnosis. A 2007 Korean study examined the prevalence and current status of MD; however, it was only able to investigate the prevalence by disease type for the same reason [2]. Thus, it is important to establish a nationwide DMD registry in Korea to examine the clinical course and management status of DMD and reach a consensus. Second, with regard to orthosis prescription, information could only be obtained from 2016 onward, when payment based on the benefits payment table was possible. Therefore, data before 2016 could not be analyzed. A further study that can analyze long-term data will be useful to understand the current status of DMD management in greater detail.

\section{Conclusions}

Overall, the current status of clinical practice for patients with DMD in South Korea have been presented. In addition to adequately reflecting the changing clinical practices in South Korea, it is expected that the findings of this study will contribute to raising awareness on the necessity of establishing a 
domestic registry in the country for patients with DMD and of developing consensus among clinicians in the long term.

\section{List Of Abbreviations}

DMD Duchenne muscular dystrophy

DXA Dual-energy X-ray absorptiometry

EMG: Electromyography

\section{Declarations}

All methods were performed in accordance with the relevant guidelines and regulations.

\section{Ethics approval and consent to participate}

The study was approved by the Institutional Review Board of 00 National University Hospital (approval number 1907-008-080) and the National Health Insurance Service of Korea (approval number REQ0000030402). The requirement for informed consent was waived because sec ondary data were used.

\section{Consent for publication}

Not applicable

Availability of data and materials

Not applicable

\section{Competing interests}

The authors declare that they have no competing interests.

\section{Funding}

Not applicable

\section{Authors' contributions}

JY, YS, HP, JK and JS carried out the studies, participated in collecting data, and drafted the manuscript. JY, JK and JS performed the statistical analysis and critically for important intellectual content. JY, JS participated in the acquisition, analysis, or interpretation of data. JY and YS drafted the manuscript. All authors read and approved the final manuscript.

\section{Acknowledgements}

Not applicable

\section{Author details}

${ }^{1}$ Department of Rehabilitation Medicine, Pusan National University School of Medicine and Biomedical Research Institute, Pusan National University Hospital, Busan, Republic of Korea

${ }^{2}$ Department of Biostatistics, Clinical Trial Center, Biomedical Research Institute, Pusan National University Hospital, Busan, Korea

\section{References}

1. Mendell JR, Shilling C, Leslie ND, Flanigan KM, al-Dahhak R, Gastier-Foster J, et al. Evidence-based path to newborn screening for Duchenne muscular dystrophy. Ann Neurol. 2012;71:304-13.

2. Choi YC, Kang DR, Kim DS. Nationwide survey of muscular dystrophy in Korea. The Report of National Institute of Health. 2007;44:438-41.

3. Vignos PJ Jr. Respiratory function and pulmonary infection in Duchenne muscular dystrophy. Isr J Med Sci. 1977;13:207-14.

4. Nigro G, Comi LI, Politano L, Bain RJ. The incidence and evolution of cardiomyopathy in Duchenne muscular dystrophy. Int J Cardiol. $1990 ; 26: 271-7$.

5. Bach JR, Martinez D. Duchenne muscular dystrophy: continuous noninvasive ventilatory support prolongs survival. Respir Care. 2011;56:744-50.

6. Passamano L, Taglia A, Palladino A, Viggiano E, D’Ambrosio P, Scutifero M, et al. Improvement of survival in Duchenne muscular dystrophy: retrospective analysis of 835 patients. Acta Myol. 2012;31:121-5.

7. Bushby K, Finkel R, Birnkrant DJ, Case LE, Clemens PR, Cripe L, et al. Diagnosis and management of Duchenne muscular dystrophy, part 1: diagnosis, and pharmacological and psychosocial management. Lancet Neurol. 2010;9:77-93. 
8. Bushby K, Finkel R, Birnkrant DJ, et al. Diagnosis and management of Duchenne muscular dystrophy, part 2: implementation of multidisciplinary care. Lancet Neurol. 2010 Mar;9(3);9;9:237

9. Birnkrant DJ, Bushby K, Bann CM, Apkon SD, Blackwell A, Brumbaugh D, et al. Diagnosis and management of Duchenne muscular dystrophy, part 1: diagnosis, and neuromuscular, rehabilitation, endocrine, and gastrointestinal and nutritional management. Lancet Neurol. 2018;17:251-67.

10. Birnkrant DJ, Bushby K, Bann CM, Alman BA, Apkon SD, Blackwell A, et al. Diagnosis and management of Duchenne muscular dystrophy, part 2: respiratory, cardiac, bone health, and orthopaedic management. Lancet Neurol. 2018;17:347-61.

11. Takeuchi F, Komaki H, Nakamura H, Yonemoto N, Kashiwabara K, Kimura E, et al. Trends in steroid therapy for Duchenne muscular dystrophy in Japan. Muscle Nerve. 2016;54:673-80.

12. Landfeldt E, Thompson R, Sejersen T, McMillan HJ, Kirschner J, Lochmüller H. Life expectancy at birth in Duchenne muscular dystrophy: a systematic review and meta-analysis. Eur J Epidemiol. 2020;35:643-53.

13. Gloss D, Moxley RT 3rd, Ashwal S, Oskoui M. Practice guideline update summary: corticosteroid treatment of Duchenne muscular dystrophy: report of the Guideline Development Subcommittee of the American Academy of Neurology. Neurology. 2016;86:465-72.

14. Merlini L, Gennari M, Malaspina E, Cecconi I, Armaroli A, Gnudi S, et al. Early corticosteroid treatment in 4 Duchenne muscular dystrophy patients: 14year follow-up. Muscle Nerve. 2012;45:796-802.

15. Lamb MM, West NA, Ouyang L, Yang M, Weitzenkamp D, James K, et al. Corticosteroid treatment and growth patterns in ambulatory males with Duchenne muscular dystrophy. J Pediatr. 2016;173:207-213.e3.

16. Griggs RC, Herr BE, Reha A, Elfring G, Atkinson L, Cwik V, et al. Corticosteroids in Duchenne muscular dystrophy: major variations in practice. Muscle Nerve. 2013;48:27-31.

17. Escolar DM, Hache LP, Clemens PR, Cnaan A, McDonald CM, Viswanathan V, et al. Randomized, blinded trial of weekend vs daily prednisone in Duchenne muscular dystrophy. Neurology. 2011;77:444-52.

18. Guglieri M, Bushby K, McDermott MP, Hart KA, Tawil R, Martens WB, et al. Developing standardized corticosteroid treatment for Duchenne muscular dystrophy. Contemp Clin Trials. 2017;58:34-9.

19. Moxley RT 3rd, Pandya S, Ciafaloni E, Fox DJ, Campbell K. Change in natural history of Duchenne muscular dystrophy with long-term corticosteroid treatment: implications for management. J Child Neurol. 2010;25:1116-29.

20. Manzur AY, Kuntzer T, Pike M, Swan A. Glucocorticoid corticosteroids for Duchenne muscular dystrophy. Cochrane Database Syst Rev. 2008;1:CD003725.

21. Larson CM, Henderson RC. Bone mineral density and fractures in boys with Duchenne muscular dystrophy. J Pediatr Orthop. 2000;20:71-4.

22. Oda T, Shimizu N, Yonenobu K, Ono K, Nabeshima T, Kyoh S. Longitudinal study of spinal deformity in Duchenne muscular dystrophy. J Pediatr Orthop. 1993;13:478-88.

23. Choi YA, Shin HI, Shin HI. Scoliosis in Duchenne muscular dystrophy children is fully reducible in the initial stage, and becomes structural over time. BMC Musculoskelet Disord. 2019;20:277.

24. Suk KS, Lee BH, Lee HM, Moon SH, Choi YC, Shin DE, et al. Functional outcomes in Duchenne muscular dystrophy scoliosis: comparison of the differences between surgical and nonsurgical treatment. J Bone Joint Surg Am. 2014;96:409-15.

25. Archer JE, Gardner AC, Roper HP, Chikermane AA, Tatman AJ. Duchenne muscular dystrophy: the management of scoliosis. J Spine Surg. 2016;2:185-94.

26. King WM, Ruttencutter R, Nagaraja HN, Matkovic V, Landoll J, Hoyle C, et al. Orthopedic outcomes of long-term daily corticosteroid treatment in Duchenne muscular dystrophy. Neurology. 2007;68:1607-13.

27. Koeks Z, Bladen CL, Salgado D, van Zwet E, Pogoryelova O, McMacken G, et al. Clinical outcomes in Duchenne muscular dystrophy: A study of 5345 patients from the TREAT-NMD DMD global database. J Neuromuscul Dis. 2017;4:293-306.

28. SenGupta DK, Mehdian SH, McConnell JR, Eisenstein SM, Webb JK. Pelvic or lumbar fixation for the surgical management of scoliosis in Duchenne muscular dystrophy. Spine (Phila Pa 1976). 2002;27:2072-9.

\section{Figures}




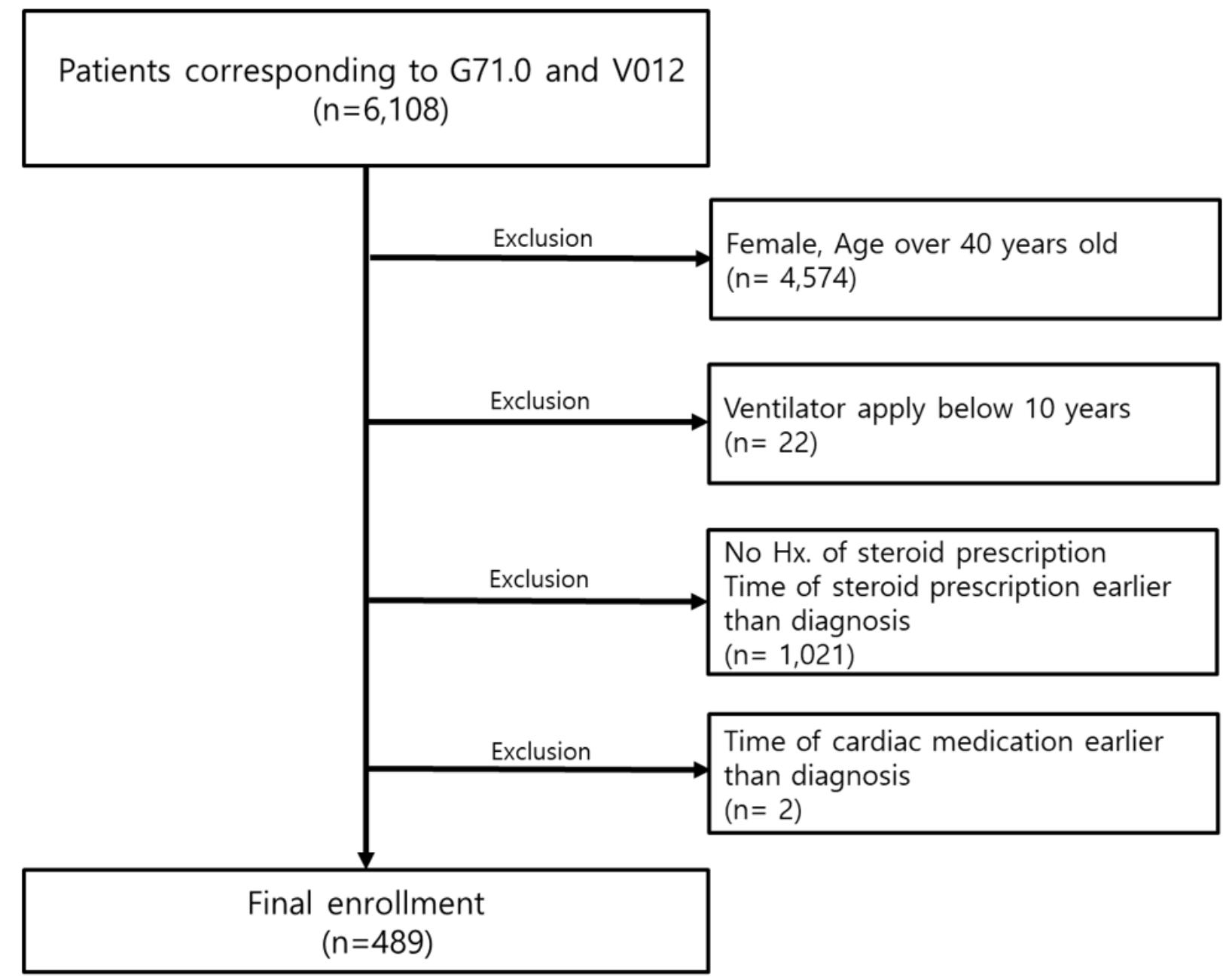

Figure 1

Flow diagram of patient inclusion and exclusion. 

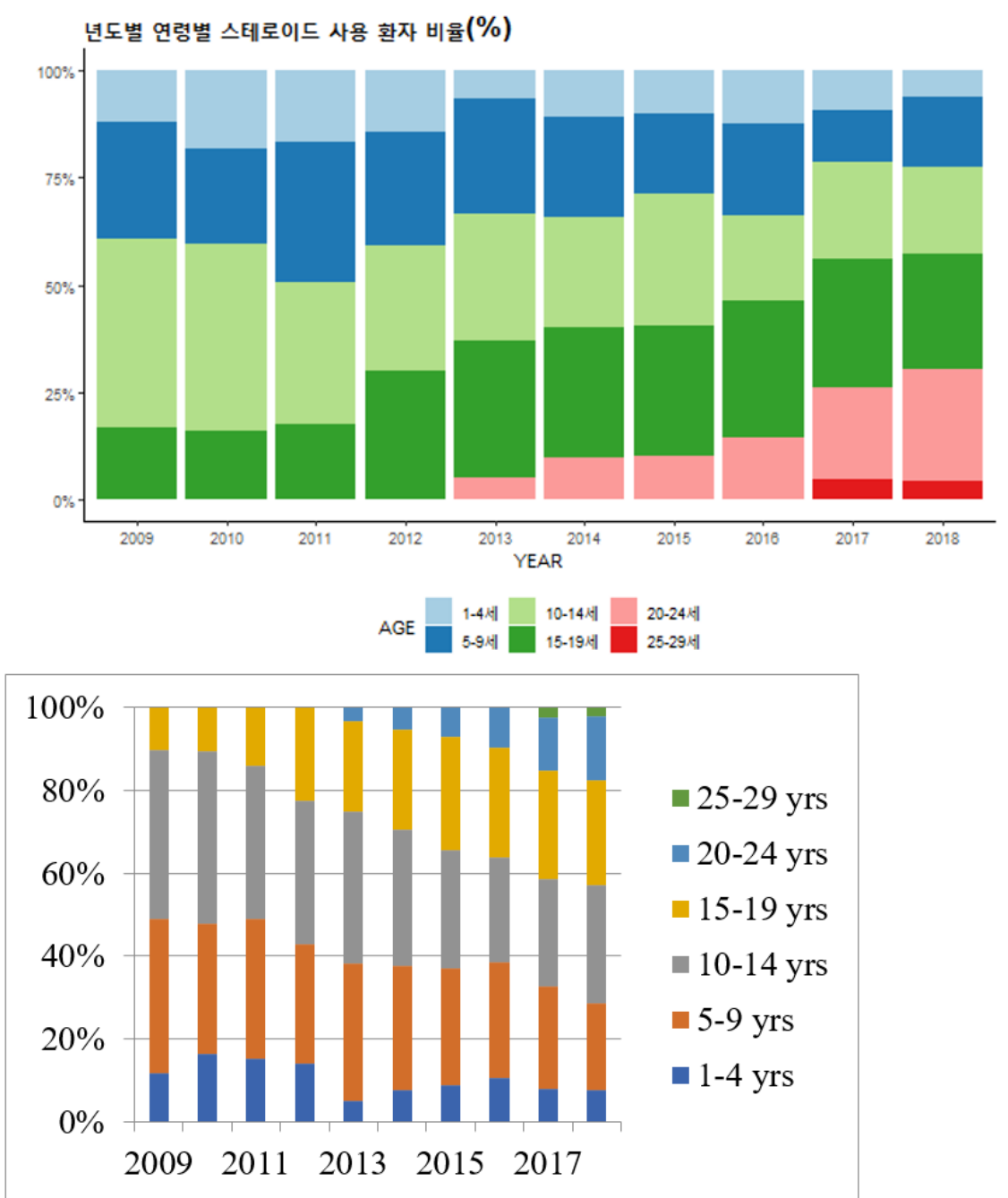

Figure 2

Corticosteroid use in South Korea based on the National Health Information Database. 


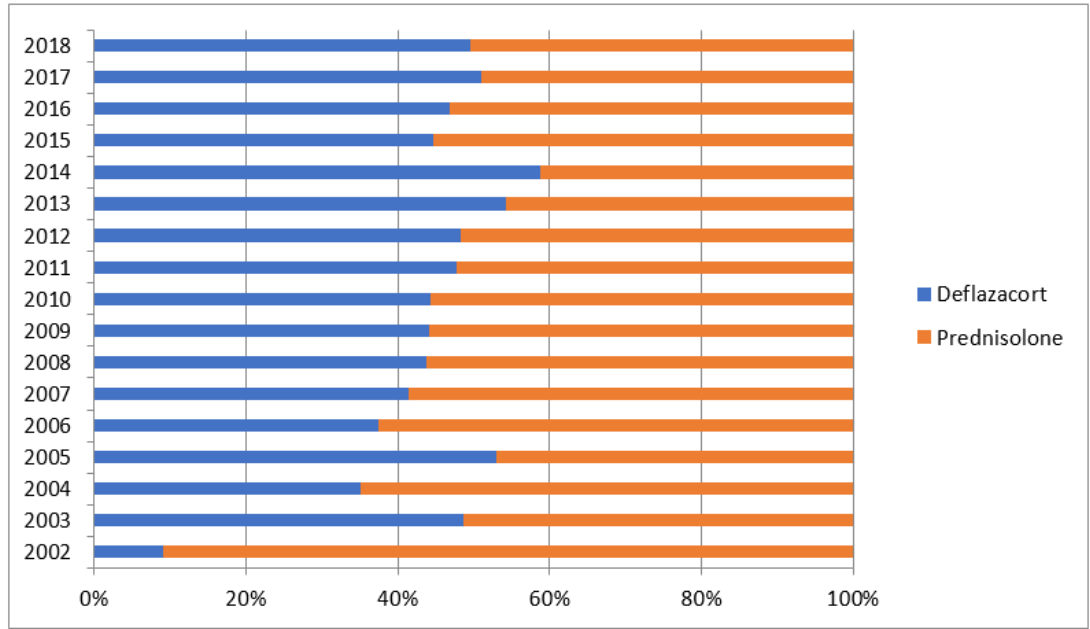

년도별 스테로이드 비율(\%)

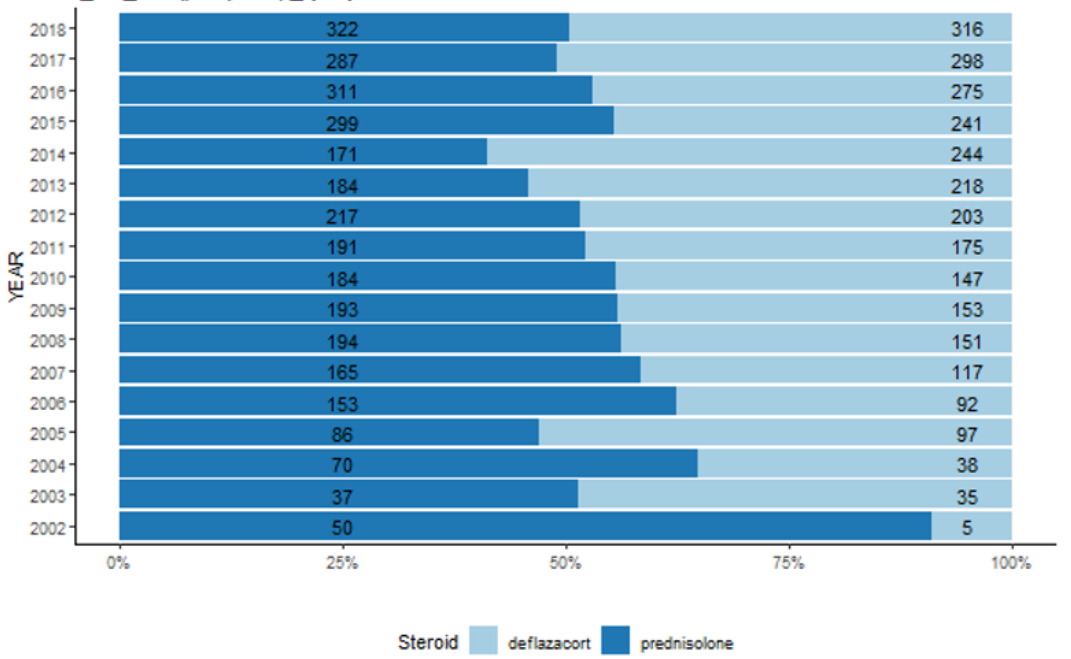

Figure 3

Proportion of deflazacort and prednisolone prescription in 2002-2018. 
스테로이드 시작 평균나이

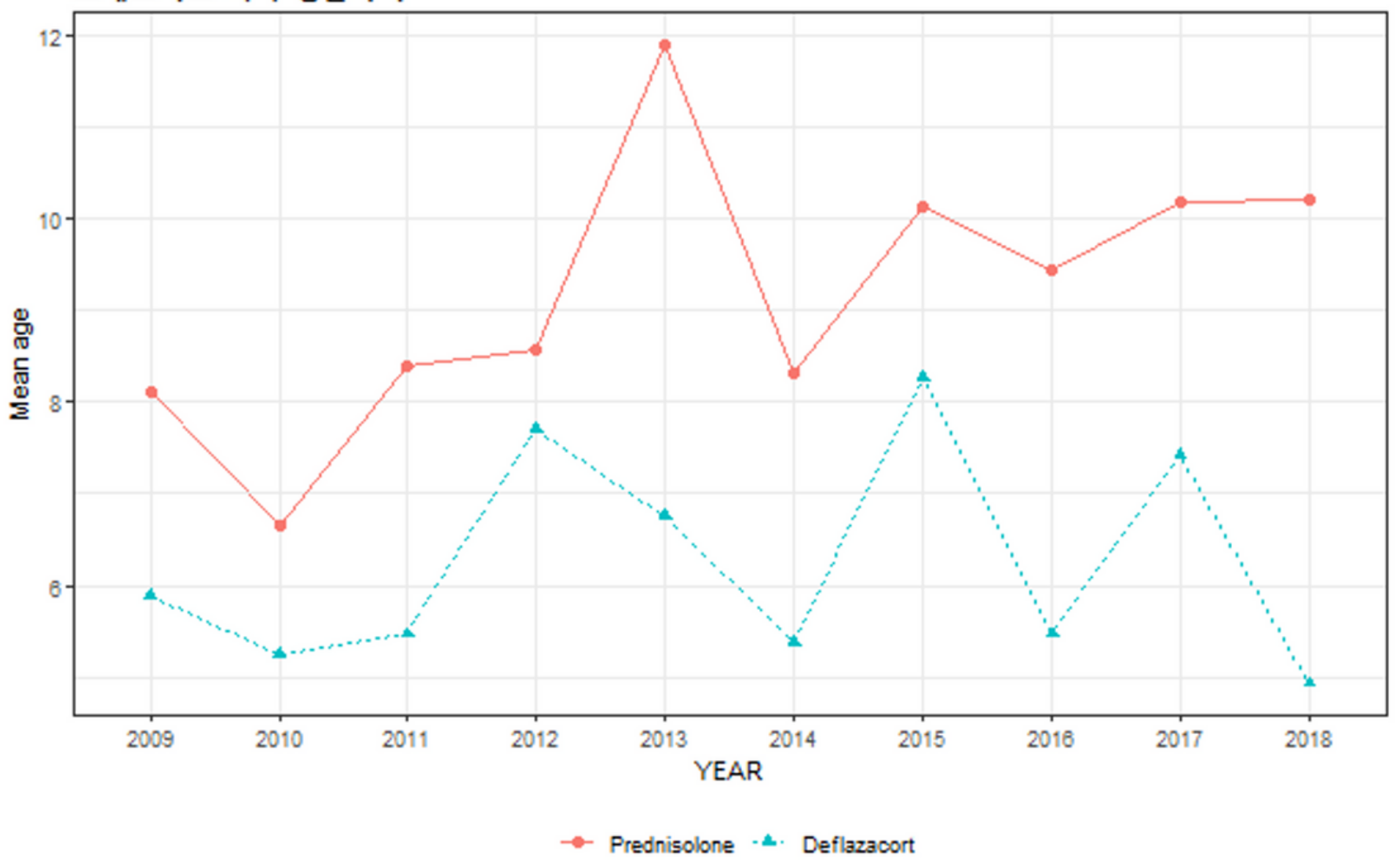

Figure 4

Mean age of patients prescribed corticosteroids in 2009-2018. 

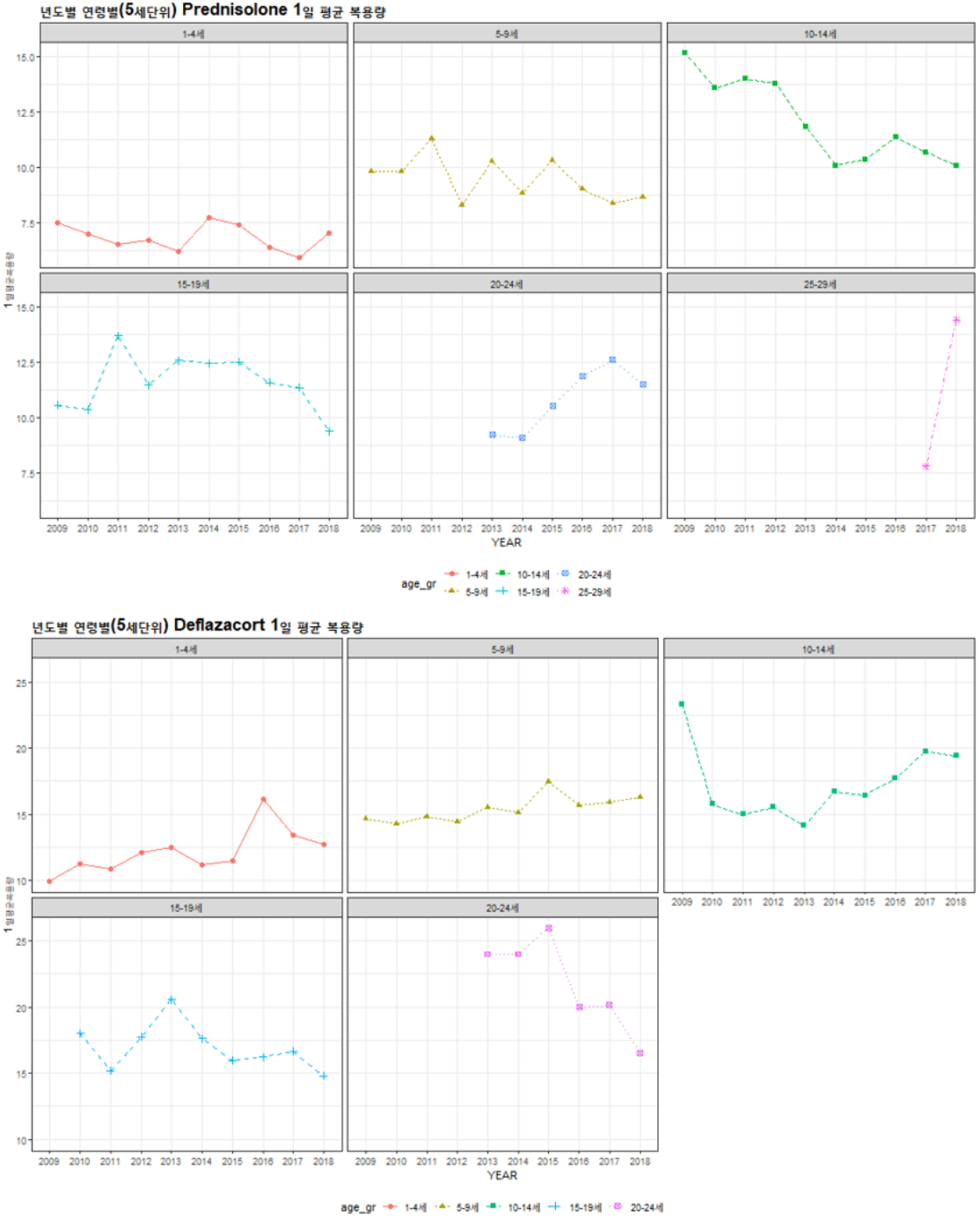

Figure 5

Mean dose of corticosteroid prescription per day in 2009-2018. 